\title{
Geochemical behavior of trace metals in the weathered tailings deposited on the riverbank: Role of $\mathrm{Fe}$ and Mn-weathering products
}

\author{
YEONGKYOO KIM
}

School of Earth Sytem Sciences, Kyungpook National University, ygkim@knu.ac.kr

Uncontrolled management of mine tailings such as mine tailings spill can cause serious environmental problems. In the upstream of the Nakdong River in Korea, the red and black deposits of weathered mine tailings, which were washed away by flood from the abandoned mines, are easily found in the several places of the riverbank.

The mineralogical changes during the weathering of deposited mine tailings and related mobility changes of trace elements were investigated by using XRD, SEM/EDS, chemical analysis, and 5-step sequential extraction method. Quartz and feldspar with minor amount of mica and Mnpyroxene were primary minerals identified in the deposits. Secondary minerals such as gypsum, bassanite, goethite, kaolinite, and jarosite were identified in the red or brown layers. Schwertmannite in the red and brown layers and Mn oxide in the black layers were also identified by SEM/EDS. Those were the weathering poroducts of pyrite and Mnpyroxene.

The order of trace metal concentrations in the tailings samples was $\mathrm{Zn}>\mathrm{Pb}>\mathrm{As}>\mathrm{Cu}>\mathrm{Cr}>\mathrm{Ni}>\mathrm{Cd}>\mathrm{Co}$. In all weathered layers, the most three abundant trace metals were $\mathrm{Zn}, \mathrm{Pb}$ and As regardless of the colors of the deposit layers. The trace metals such as $\mathrm{Cd}, \mathrm{Cr}$, and $\mathrm{Ni}$ were mainly present in the cation exchangeable fraction (step 1) and the faction bound to carbonate (step 2), although the concentration of each element was low, indicating that these elements are potentially toxic compared with other elements. In case of $\mathrm{Co}, \mathrm{Cd}, \mathrm{Ni}, \mathrm{Pb}$, and $\mathrm{Zn}$, large percentages of these metals were in the faction bound to Fe/Mn oxides (step 3), especially for the samples from black layers. These metals were supposed to be coprecipitated with $\mathrm{Fe}$ and $\mathrm{Mn}$ oxides or sorbed on the surface of those phases, which was also observed by SEM/EDS analysis for $\mathrm{Pb}$ and $\mathrm{Zn}$. The black color and high content of $\mathrm{Mn}$ for the samples from black layers strongly suggest that the amorphous Mn oxide plays a significant role in fixing trace metals. Therefore, weathering of both pyrite and Mn pyroxene can reduce the potential toxicity in the severely weathered tailings and related systems. 